\title{
FAKTOR DETERMINAN YANG MEMPENGARUHI PRE MARRIED SYNDROM
}

\author{
DIYAH AYU L \\ Jalan Raya Kaligawe Km.4 Semarang \\ Diah.l@unissula.ac.id
}

\begin{abstract}
ABSTRAKSI
Masa Remaja merupkan masa yang sangat penting dalam proses perkembangan. Remaja sekarang dan remaja dahulu sangatlah berbeda, khususnya remaja wanita. Wanita sekarang cenderung menunda pernikahannya. Sedangkan wanita jaman dahulu lebih cenderung menikah di usia $<20$ tahun. Ada faktor yang menyebabkan wanita sekarang menunda pernikahannya, salah satu faktor tersebut adalah peer group, faktor pendidikan dan konsumsi media. Melihat hal tersebut peneliti tertarik untuk mengukur bagaimana "Faktor Determinan yang Mempengaruhi pre Married Syndrom”.

Penelitian ini bertujuan untuk mengetahui faktor determinan yang memepengaruhi pre married syndrom terhadap wanita di Desa Sriwulan. Teori yang dipakai dalam penelitian ini yaitu, teori sosial and communicative anxiety dimana teori ini menjelaskan tentang kecemasan komunikasi dan kecemnasan sosial sebagai keengganan berkomunikasi.. Penelitian ini menggunkan tipe penelitian studi korelasional. Data yang dikumpulkan dari kuesioner, wawancara, dan kapustakaan. Sample yang diambil adalah wanita Desa Sriwulan yang belum menikah dengan teknik purposive sampling yaitu 95 responden.

Hasil penelitian berdasarkan analisis korelasi didapat untuk peer group -0,70782 berada pada tingkat tinggi, Faktor pendidikan $-0,5394$ berada pada tingkat sedang, dan konsumsi media $-0,5320$ yang berada pada tingkat sedang. Sedangkan pada uji hipotesis didapat bahwa, H0 ditolak dan Ha diterima, artinya ada hubungan signifikan antara pre married syndrom dengan faktor determinan.
\end{abstract}

Kata kunci: pre married syndrom, peer group, faktor pendidikan, konsumsi media, kecemasan sosial.

\section{Abstract}

Adolescence is a crucial time in the development process. Current and former teen teens are very different, especially young women. Women are now more likely to delay marriage. While women are more likely to marry antiquity at age $<20$ years. There are factors that cause women are now postponing marriage, one such factor is the peer group, educational factors and media consumption. Seeing that researchers interested in measuring how "Determinant Factors Affecting Pre Married Syndrome".

This study aims to determine the factors that affect determinants of the syndrome of pre married women in the village Sriwulan. The theory used in this study, namely, the theory of social and communicative anxiety in which this theory explains communication 
apprehension and social anxiety as a reluctance to communicate. This research study using the type of correlational studies. Data were collected from questionnaires, interviews, and reference books. Samples taken Sriwulan village woman who is not married to the purposive sampling technique that is 95 respondents.

The results based on the analysis of correlation obtained for the peer group is at a high level -0.70782, -0.5394 educational factors are at moderate levels, and media consumption -0.5320 which is at the moderat level of the hypothesis test obtained that, HO rejected and Ha is accepted, it means there is a significant relationship between pre married syndrome with determinant factor.

Keywords: pre married syndrom, peer group, educational factors, media consumption, social anxiety

\section{PENDAHULUAN}

\section{I.1 Latar Belakang}

Masa Remaja merupakan masa yang sangat penting dalam proses perkembangan. Karena itu perkembangan masa remaja sudah seharusnya mendapatkan perhatian dari berbagai pihak, terutama lingkungan terdekatnya. Salah satu bagian terpenting dari perkembangan remaja adalah perkembangan dalam kehidupan sosialnya..

Menurut data dari BPS Kab. Demak menyatakan bahwa selama setahun belakangan ini $0,2 \%$ wanita Demak menikah di bawah usia 17 tahun. Ini membuktikan bahwa, wanita sekarang mulai mempertanyakan berapa umur ideal wanita untuk menikah. Karena di jaman sekarang yang semakin maju wanita yang menikah di usia muda cenderung tidak bahagia. Usia muda cenderung belum matang dalam berbagai hal.

Terbukti pula dengan adanya data dari BPS Kab. Demak yang menyatakan bahwa anak usia sekolah di Demak sangat tinggi yaitu anak usia 16-18 tahun sebesar $51,63 \%$ dengan rincian laki-laki 17,104 dan perempuan 18,259 , sedangkan anak yang usia $>19$ tahun sebesar 46,74\%. Ini membuktikan bahwa anak usia remaja di Kab. Demak memilih untuk mengejar pendidikan ketimbang menikah di usia muda.

Pre marreid syndrom merupakan suatu godaan atau cobaan pra menikah, Sindrom ini lebih mengarah pada sisi psikologis seseorang dimana rasa cemas, takut karena belum cukup umur, keinginan meraih prestasi, dan mengejar karir. Pre Married Syndrom ini dapat dipengaruhi oleh beberapa faktor diantaranya, komunikasi oleh peer Group, tingkat pendidikan, jenis pekerjaan, komunikasi didalam keluarga, dan lain sebagainya.

\section{I.2 RUMUSAN MASALAH}

Berdasarkan uraian diatas maka perumusan masalah dalam penelitian ini untuk mengetahui Faktor determinan apa saja yang mempengaruhi pre married syndrom terhadap wanita di desa Sriwulan?

\subsection{TUJUAN PENELITIAN}

Untuk mengetahui faktor
determinan yang mempengaruhi pre


married syndrom terhadap wanita di Desa Sriwulan.

\section{I.4 KERANGKA TEORI}

Penelitian dengan pendekatan positivistik berasumsi bahwa kebenaran objektif dapat dicapai dan bahwa proses meneliti untuk menemukan kebenaran dapat dilakukan, paling tidak dengan bebas dari nilai. Tradisi ini mendukung metode ilmu alam, dengan tujuan untuk membentuk teori yang bersifat umum dalam mengatur interaksi manusia. Peneliti pada tradisi intelektual ini berusaha objektif dan bekerja dalam kontrol, atau arah ke konsep penting yang ada dalam teori. Dengan kata lain, ketika peneliti bergerak untuk melakukan pengamatan, dengan hati-hati membangun situasi sehingga akan memudahkan peneliti untuk membuat pernyataan yang relatif akan mengenai elemennya (Richard West, 2008: 75).

Menurut Joseph A. Devito (1997), komunikasi antarpribadi itu adalah proses pengiriman dan penerimaan pesan-pesan antara dua orang atau diantara sekelompok kecil orang-orang, dengan beberapa efek dan beberapa umpan balik seketika. Komunikasi antarpersonal dinilai paling baik dalam kegiatan mengubah sikap, kepercayaan, opini, dan perilaku komunikan.

Teori yang diangkat dalam penelitian ini yaitu Teori sosial and communicative anxiety. Teori ini menjelaskan tentang kecemasan komunikasi dan kecemasan sosial sebagai keengganan berkomunikasi, ketakutan tersebut muncul dari dalam diri kita atau merupakan bagaian dari sifat individu itu sendiri.

Kecemasan merupakan pengalaman subjektif yang tidak menyenangkan mengenai kekhawatiran atau keterhantungan berupa cemas, tegang dan keadaan tertentu, yaitu menghadapi situasi yang tidak pasti dan tidak menentu terhadap kemampuannya dalam menghadapi objek tersebut.

$$
\text { Muchlas }
$$

mendefinisikan istilah kecemasan sebagai sesuatu pengalaman subjektif mengenai ketegangan mental kesukaran dan tekanan yang menyerrtai konflik atau ancaman. Sementara McCroskey,dkk. (1997) mengemukakan bahwa kecemasan komununikasi adalah masalah yang serius bagi orang banyak. Ada dua perspektif yang mempengaruhi kecemasan komunikasi, yaitu perspektif cognitively dan perspektif behaviorally.

Kecemasan komunikasi yang normal bukanlah suatu masalah, tetapi kecemasan komunikasi yang berlebihan tentunya akan menjadi masalah yang serius, karena dapat membuat permasalahan seseorang menjadi lebih rumit dan menimbulkan ketidaknyamanan, sehingga seseorang sebisa mungkin akan menghindari setiap transaksi komunikasi. Terdapat 
dua tingkatan dalam kecemasan komunikasi :

\section{a. Trate Apprehension}

Perasaan takut pada semua situasi komunikasi (stabil). Orang yang menderita TA berubah menjadi pribadi yang pasif. Mereka menghindari situasi komunikasi terutama yang berhubungan dengan orang banyak.

\section{a. State Apprehension}

Perasaan takut/cemas pada situasi komunikasi tertentu. Sehingga sifatnya situasional, kemunculannya tergantung pada situasi dimana seseorang akan melakukan tindak komunikasi.Seseorang bisa jadi takut/cemas pada saat public speaking, tetapi ia tidak mempunyai kesulitan dengan komunikasi diadik. Disebut juga Person-group Communication Apprehension.

\begin{tabular}{lcr}
\multicolumn{2}{c}{ Penelitian ini selain } \\
menggunakan teori social and \\
communicative anxiety & juga
\end{tabular} menggunakan teori Uncertainty Reduction Theory. Dimana teori ini menekankan bahwa komunikasi digunakan untuk mengurangi ketidakpastian diantara dua orang asing yang terlibat dalam pembicaraan satu sama lain untuk pertama kali.

Terdapat dua tipe ketidakpastian:

1. Ketidakpastian Kognitif (Cognitive uncertainty) merupakan tingkatan ketidakpastian yang diasosiasikan dengan keyakinan dan sikap.
2. Ketidakpastian Perilaku (Behavioral uncertainty), dilain pihak berkenaan dengan luasnya perilaku yang dapat diprediksikan dalam situasi yang diberikan.

Dalam penelitian ini seorang yang mengalami kecemasan untuk menikah ketika bertemu dengan orang lain akan mengalami ketakutan untuk berkomunikasi dengan orang lain, sehingga tingkat ketidakpastian tersebut akan meningkat. Ketika ketidakpastian menikat maka afiliatif non verbal akan mengalami peningkatan.

Tingkat ketidakpastian yang tinggi dalam sebuah hubungan menyebabkan penurunan tingkat keintiman dari isi komunikasi. Tingkat ketidakpastian yang rendah menghasilkan tingkat keintiman yang tinggi. Aksioma ni memeprlihatkan hubungan yang negative antara ketidakpastian dan tingkat keintiman.

\section{I.5 HIPOTESIS PENELITIAN}

Hipotesis merupakan jawaban sementara terhadap masalah yang masih bersifat praduga karena masih harus dibuktikan kebenarannya. Dani Vardiansyah (2008 : 10). Oleh karenanya, hipotesis dalam penelitian ini yaitu adanya pengaruh antara Faktor Determinan dengan $P^{\prime} r e$ married syndrom pada wanita di Desa Sriwulan. Semakin banyak faktor yang mempengaruhi pre married syndrom kemungkinan besar wanita akan semakin cemas untuk menikah muda. 


\section{I.6 METODOLOGI PENELITIAN}

\subsubsection{Tipe Penelitian}

Tipe penelitian yang dipakai dalam penelitian ini adalah studi korelasional ( menyatakan hubungan antara suatu variabel dengan variabel yang lainnya), yaitu melihat faktor determinan yang mempengaruhi pre married syndrom pada wanita.

\subsubsection{Populasi dan Sampel}

Populasi adalah jumlah keseluruhan dari unit analisa yang ciri-cirinya akan di duga. Populasi dalam penelitian ini yaitu remaja wanita yang berada di daerah Desa Sriwulan yang berusia 20-29 tahun.

\section{Tabel ditribusi frekuensi}

\begin{tabular}{|c|c|c|c|}
\hline Wilayah & $\begin{array}{c}\text { Usia } \\
20-24 \\
\text { tahun }\end{array}$ & $\begin{array}{c}\text { Usia } \\
25-29 \\
\text { tahun }\end{array}$ & Total \\
\hline Sriwulan & 594 & 489 & 1080 \\
\hline
\end{tabular}

Sumber : Data Monografi Desa Sriwulan

Sampel adalah sebagian dari populasi yang karakteristiknya hendak diselidiki dan dianggap bisa mewakili keseluruhan populasi (Kriyantono, 2010:154). Sampel dikenal dengan populasi sasaran. Pada penelitian ini peneliti menentukan jumlah sampel yang akan diteliti adalah 95 responden.

\subsubsection{Teknik Sampling}

Penelitian ini menggunakan rancangan sampling nonprobabilitas. Nonprobabilitas adalah cara pengambilan sample dimana semua anggota polulasi belum tentu memiliki peluang yang sama untuk dipilih menjadi sample ( Rachmad, 2010 ).Dalam sampling nonprobabilitas, teknik yang digunakan adalah purposive sampling.

Teknik ini mencangkup orangorang diseleksi atau berdasarkan kriteria tertentu yang dibuat periset berdasarkan tujuan riset, sedangkan orang-orang dalam polulasi yang tidak sesuai dengan kriteria tersebut dijadikan sampel. ( Kriyantono, $2010: 158$ )

Kriteria sampel dalam penelitian ini adalah :

1. Remaja wanita

2. Sudah bekerja/ Masih menempuh pendidikan di Perguruan tinggi

3. Tidak pada masa sekolah ( SD, SMP, SMA )

4. Berusia dibawah 20 tahun

\subsubsection{Jenis dan Sumber data}

\subsubsection{Data primer}

Data primer adalah data yang didapatkan atau dikumpulkan secara sendiri. Data primer penelitrian ini diperoleh melalui kuisioner dan wawancara langsung.

\subsubsection{Data sekunder}

Data sekunder yaitu data dokumentasi yang diperoleh dari berbagai pihak terkait, hasil penelitian orang lain, dan artikel yang relevan dengan masalah yang 
diteliti. Data sekunder dalam penelitian ini adalah BPS Kab. Demak.

\section{PEMBAHASAN}

\subsection{Hasil Penelitian}

Hasil dari penelitian ini yang diperoleh melalui hasil kuisioner, dengan hasil sebagi berikut:

\subsubsection{Peer Group dengan Pre Married} Syndrom

Nilai pada pre married syndrom dan peer group tinggi hanya $1 \%$, pre married syndrom tinggi dan peer group sedang sebesar 14\%. Nilai untuk pre married syndrom sedang dan peer group tinggi hanya $1 \%$, sedangkan pre married syndrom rendah dan peer group tinggi $14 \%$. Dan pre married syndrom sedang dan peer group sedang sebesar $62 \%$, nilai untuk pre married synrom sedang dan peer group rendah hanya $2 \%$.

\subsubsection{Faktor pendidikan dan Pre married} Syndrom

Didapat nilai untuk pre married syndrom dan faktor pendidikan tinggi sebesar $11 \%$, pre married syndrom tinggi dan faktor pendidikan sedang hanya $5 \%$, untuk pre married syndrom sedang dan faktor pendidikan sedang sebesar $41 \%$, pre married syndrom sedang dan faktor pendidikan tinggi $28 \%$, sedangkan untuk pre married syndrom rendah dan faktor pendidikan tinggi $11 \%$, untuk pre married syndrom rendah dan faktor pendidikan tinggi sebesar $4 \%$.
2.1.3 Konsumsi Media dengan Pre Married Syndrom

Nilai tabel silang untuk pre married syndrom dan konsumsi media tinggi sebesar 7\%, nilai pre married syndrom dan konsumsi media sedang $47 \%$, untuk nilai pre married syndrom tinggi dan konsumsi media rendah sebesar 9\%. Nilai pre married syndrom sedang dan konsumsi medai tinggi sebesar $20 \%$, untuk pre married syndrom sedang dan konsumsi media rendah hanya 1\%. Pre married syndrom rendah dan konsumsi media tinggi hanya $1 \%$, pre married syndrom rendah dan konsumsi media sedang sebesar $13 \%$, dan untuk nilai pre married syndrom rendah dan konsumsi media rendah hanya $2 \%$.

\subsection{Uji Hipotesis}

2.2.1 Analisis Regrensi

Untuk melihat besarnya hubungan variabel pre married syndrom terhadap faktor- faktor determinan secara sendirisendiri/parsial digunakan Uji t, sedangkan untuk melihat besarnya hubungan, digunakan angka beta, atau Standardized Coeffectent di bawah ini :

Coefficients $^{\mathrm{a}}$

\begin{tabular}{|l|l|c|c|c|c|}
\hline \multirow{2}{*}{ Model } & \multicolumn{2}{|c|}{$\begin{array}{c}\text { Unstandardized } \\
\text { Coefficients }\end{array}$} & $\begin{array}{c}\text { Stand } \\
\text { ardize } \\
\mathrm{d} \\
\text { Coeffi } \\
\text { cients }\end{array}$ & $\mathrm{T}$ & Sig. \\
\cline { 1 - 3 } & B & $\begin{array}{c}\text { Std. } \\
\text { Error }\end{array}$ & Beta & & \\
\hline
\end{tabular}




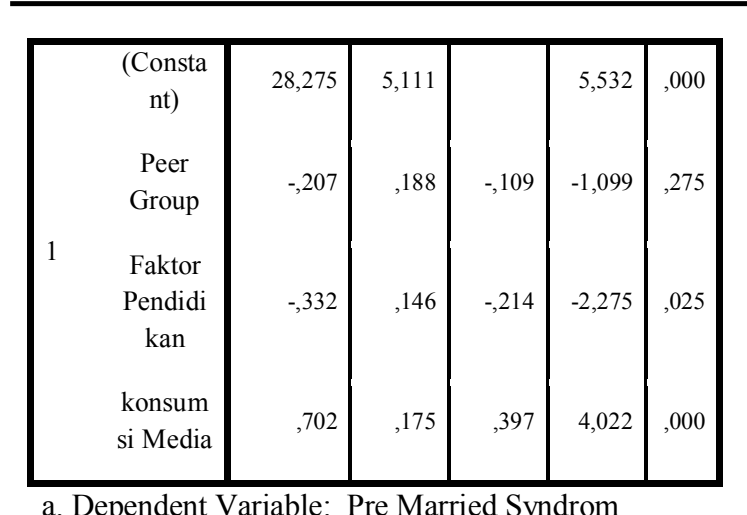

a. Dependent Variable: Pre Married Syndrom

Untuk melihat apakah ada hubungan linier antara pre married syndrom terhadap faktor determinan, dilakukan dengan langkahlangkah analisis sebagai berikut :

Hasil penghitungan dengan menggunakan SPSS diperoleh $\mathrm{t}$ penelitian untuk peer group sebesar -1,099, faktor pendidikan $-2,275$, dan konsumsi media 4,022.

Didasarkan dari hasil perhitungan diperoleh angka sebagai berikut:

$\mathrm{X} 1: \mathrm{t}$ penelitian $-1,099>\mathrm{t}$ tabel sebesar 0,67720 maka H0 ditolak, dan Ha diterima. Artinya ada hubungan linier antara pre married syndrom terhadap peer group pada wanita Sriwulan. Besarnya hubungan pre married syndrom terhadap peer group sebesar - 0,109 atau -10\%

$\mathrm{X} 2: \mathrm{t}$ penelitian $-2.275>\mathrm{t}$ tabel sebesar 1.98638 maka $\mathrm{H} 0$ ditolak, dan Ha diterima . artinya ada hubungan linier antara pre married syndrom terhadap faktor pendidikan pada wanita sriwulan. Besarnya hubungan pre married syndrom terhadap peer group sebesar -2.275 atau $-2.16 \%$

$\mathrm{X} 3: \mathrm{t}$ penelitian $4.022>\mathrm{t}$ tabel sebesar 2.36803 maka H0 ditolak, dan Ha diterima. Artinya ada hubungan linier antara pre married syndrom terhadap konsumsi media sebesar 4,022 atau $3,82 \%$

\subsection{Analisis Korelasi}

Koefisien korelasi dapat juga digunakan untuk mengetahui arah hubungan antara dua variabel. Tanda $(+$ dan -) yang terdapat pada koefisien korelasi menunjukkan arah hubungan antara dua variabel. Tanda negatif (-) pada koefisien korelasi menujukkan

hubungan yang berlawanan arah. Tanda positif $(+)$ pada koefisien korelasi menunjukkan hubungan yang searah.

Untuk melihat hubungan korelasi antara pre married syndrom terhadap faktor-faktor determinan pada wanita Sriwulan. Korelasi yang didapat antara faktor determinan yaitu peer group, faktor pendidikan, dan konsumsi media terhadap pre married syndrom pada perhitungan diatas sebagai berikut:

1. Peer group memiliki koefisien sebesar - 0,70782 menunjukkan bahwa hubungan $\mathrm{X}_{1}$ dengan $\mathrm{Y}$ ketika variabel bebas lainnya konstans, adalah tinggi/kuat.

2. Faktor pendidikan memiliki koefisien sebesar -0,5394 menunjukkan bahwa hubungan $\mathrm{X}_{2}$ dengan $\mathrm{Y}$ ketika variabel bebas lainnya konstans adalah sedang.

3. Konsumsi media memiliki koefisien sebesar -0,5320 menunjukkan bahwa hubungan $\mathrm{X}_{3}$ dengan $\mathrm{Y}$ ketika variabel bebas lainnya konstan, adalah sedang.

Secara teori penelitian ini berkaitan dengan teori yang dipilih yaitu social and communicative anxiety karena teori ini mengenali dari bentuk-bentuk gejala dalam 
bentuk kecemasan social. Dengan kata lain, orang yang memiliki kecemasan social dapat dilihat dari gejala-gejala karena kecemasan social memiliki mekanisme secara skematis yang menghasilkan perilaku.

Kecemasan komunikasi yang normal bukanlah suatu masalah, tetapi kecemasan komunikasi yang berlebihan tentunya akan menjadi masalah yang serius, karena dapat membuat permasalahan seseorang menjadi lebih rumit dan menimbulkan ketidaknyamanan, sehingga seseorang sebisa mungkin akan menghindari setiap transaksi komunikasi. Terdapat dua tingkatan dalam kecemasan komunikasi :

\section{Trate Apprehension}

Perasaan takut pada semua situasi komunikasi (stabil). Orang yang menderita TA berubah menjadi pribadi yang pasif. Mereka menghindari situasi komunikasi terutama yang berhubungan dengan orang banyak.

\section{State Apprehension}

Perasaan takut/cemas pada situasi komunikasi tertentu. Sehingga sifatnya situasional, kemunculannya tergantung pada situasi dimana seseorang akan melakukan tindak komunikasi.Seseorang bisa jadi takut/cemas pada saat public speaking, tetapi ia tidak mempunyai kesulitan dengan komunikasi diadik. Disebut juga Person-group Communication Apprehension.

Dalam uncertainty reduction theory terdapat fase pengurangan untuk mengatasi rasa ketidak pastian yang ada dalam diri:

1. Memulai interaksi,

2. Berkomunikasi,

3. Penentuan sikap (melanjutkan hubungan atau tidak

Tujuan dari penelitian ini untuk mengetahui faktor determinan yang mempengaruhi pre married syndrom dan dari hasil kuesioner melalui sofware SPSS maupun secara manual diketahui bahwa nilai korelasi untuk peer group sebesar 0,70782 nilai ini menunjukkan nilai tinggi/kuat . Korelasi ini menunjukan angka yang negatif artinya korelasi menunjukkan arah yang berlawanan pada hubungan antara variabel. Semakin tinggi nilai peer group maka semakin tinggi pula nilai pre married syndrom. Untuk Faktor pendidikan nilai korelasi sebesar $-0,5394$ nilai ini menunjukkan sedang, korelasi ini menunjukkan angka negarif artinya korelasi menunjukkan arah yang berlawanan pada hubungan antara variabel. Semakin tinggi Faktor pendidikan semakin tinggi pula nilai pre married syndrom. Sedangkan konsumsi media memiliki nilai korelasi sebesar 0,5320 nilai ini menunjukkan sedang, korelasi ini menunjukkan arah yang berralawanan pada hubungan antara variabel. Sehingga semakin tinggi nilai konsumsi media maka semakin tinggi pula pre married syndrom.

Dari tabel silang didapat nilai pada pre married syndrom dan peer group tinggi hanya $1 \%$, pre married tinggi dan peer group sedang sebesar 14\%. Nilai untuk pre married syndrom sedang dan peer group tinggi hanya $1 \%$, sedangkan pre married syndrom rendah dan peer group tinggi $14 \%$. 
Dan pre married syndrom sedang dan peer group sedang sebesar $62 \%$, nilai untuk pre married synrom sedang dan peer group rendah hanya $2 \%$.

Dari tabel silang didapat nilai untuk pre married syndrom dan faktor pendidikan tinggi sebesar $11 \%$, pre married syndrom tinggi dan faktor pendidikan sedang hanay $5 \%$, untuk pre married syndrom sedang dan faktor pendidikan sedang sebesar $41 \%$, pre married syndrom sedang dan faktor pendidikan tinggi $28 \%$, sedangkan untuk pre married syndrom rendah dan faktor pendidikan tinggi $11 \%$, untuk pre marrieds yndrom rendah dan faktor pendidikan tinggi sebesar $4 \%$.

Nilai tabel silang untuk pre married syndrom dan konsumsi media tinggi sebesar $7 \%$, nilai pre married syndrom dan konsumsi media sedang $47 \%$, untuk nilai pre married syndrom tinggi dan konsumsi media rendah sebesar $9 \%$. Nilai pre married syndrom sedang dan konsumsi medai tinggi sebesar $20 \%$, untuk pre married syndrom sedang dan konsumsi media rendah hanya $1 \%$. Pre married syndrom rendah dan konsumsi media tinggi hanya $1 \%$, pre married syndrom rendah dan konsumsi media sedang sebesar $13 \%$, dan untuk nilai pre married syndrom rendah dan konsumsi media rendah hanya $2 \%$.

Hal tersebut terjadi karena wanita Sriwulan telah mengikuti perkembangan zaman dimana wanita Sriwulan sekarang cenderung menunda pernikahan dengan memilih untuk melanjutkan ke jenjang ynag lebih tinggi. Hal tersebut juga dipengaruhi oleh peer group dimana wanita Sriwulan mudah berpengaruh dengan temsn sehingga teman mengatakan A yang lainnya juga akan mengikuti.
Faktor pendidikan juga ikut mempengaruhi wanita Sriwulan untuk menunda pernikahannya di usia muda dapat terlihat pada tabel 3.18 yang menyatakan bahwa sebesar $65 \%$ responden menyetujui pernyataanbahwa pendidikan yang tinggi akan mengantarkan mereka ke masa depan yang lebih baik.

Selain peer group dan faktor pendidikan yang berpengaruh konsumsi media juga mempengaruhi wanita Sriwulan untuk menunda pernikahannya di usia muda, terlihat dengan responden yang menyatakan bahwa mereka menonton televisi setiap hari, ini membuktikan bahwa wanita Sriwulan mudah terpengaruh dengan terepaan yang ada di media.

Menunda pernikahan di usia muda bisa diartikan bahwa wanita sekarang cenderung takut untuk menikah, terlihat pula dengan teori dalam penelitian ini yang menyatakan bahwa pada tingkatan Trate Aprprehension orang yang menderita kecemasan akan mengalami ketegangan maupun kegelisahan yang tidak pada tempatnya, baik dalam komunikasi lisan, tulisan, ataupun keduanya. Pada tingkatan State Apprehension orang yang mengalami ketakutan akan cenderung takut ataupun cemas pada situasi komunikasi tertentu. Sehingga sifatnya situasional, munculnya tergantung pada situasi dimana orang tersebut akan melakukan tindakan komunikasi.

Dalam penelitian ini wanita yang takut menikah muda masuk kedalam tingkatan State aprrehension karena wanita Sriwulan memiliki ciri dimana wanita Sriwulan ingin melanjutkan sekolah ke jenjang yang lebih tinggi, cenderung pendiam didalam masyarakat sehingga 
wanita tersebut tidak pernah mengikuti acara perkumpulan maupun organisasi yang ada di lingkungan sekitar.

Sehingga seorang yang mengalami ketidakpastian atas kecemasan yang dialaminya seharusnya pasif dengan keadaan sekitar dengan cara mencari tahu tentang keadaan lingkungan terdekatnya, yang kedua dengan cara aktif dengan mencari informasi-informasi yang belum ia ketahui dari sumber lain, dan yang terakhir dengan cara interaktif dengan mencari tahu secara langsung dari objek maupun lawan komunikasi.

\section{PENUTUP}

\subsection{Kesimpulan}

Penelitian ini dimaksudkan untuk mengetahui " Faktor Determinan yang Mempengaruhi Pre marrieds syndrom" khususnya wanita di Desa Sriwulan. Setelah penullis melakukan penelitian melalui pengumpulan data, analisis data dan teori yang ada dihunakan dalam penelitian, maka penelitian ini dapat disimpulkan sebagai berikut:

1. Hubungan antara variabel :

a. Ada pengaruh antara faktor peer group terhadap pre married syndrom.

b. Ada pengaruh antara faktor pendidikan terhadap pre married syndrom.

c. Ada pengaruh antara konsumsi media terhadap pre married syndrom.

2. Keeratan hubungan antara variabel $X$ dan Y

a. Keeratan antara Peer group $\left(\mathrm{X}_{1}\right)$ dengan pre married syndrom ( $\mathrm{Y}$ ) adalah- $\quad 0,70782$ menunjukkan bahwa hubungan $\mathrm{X}_{1}$ dengan $\mathrm{Y}$ ketika variabel bebas lainnya konstans, adalah tinggi/kuat.. Tanda negatif pada koefisien korelasi ini menunjukkan adanya hubungan yang berlawanan.

b. Keeratan antara Faktor pendidikan ( $\mathrm{X}_{2}$ ) dengan pre married syndrom ( Y) adalah -0,5394, menunjukkan bahwa hubungan $\mathrm{X}_{2}$ dengan $\mathrm{Y}$ ketika variabel bebas lainnya konstans adalah sedang. Tanda negatif pada koefisien korelasi menunjukkan adanya hubungan yang berlawanan antara variabel ( $\mathrm{X}_{2}$ ) dengan variabel ( $\mathrm{Y}$ )

c. Keeratan hubungan antara Konsumsi media ( X3 ) dengan pre married syndrom (Y) adalah 0,5320 menunjukkan bahwa hubungan $\mathrm{X}_{3}$ dengan $\mathrm{Y}$ ketika variabel bebas lainnya konstan, adalah sedang. Tanda negatif pada koefisien korelasi menunjukkan adanya hubungan yang berlawanan antara variabel ( $\mathrm{X} 3$ ) dengan variabel (Y).

3. Berdasarkan hasil penelitian dan pembahasan maka hasil yang didapat adalah :

a. Ha pada variabel $\left(\mathrm{X}_{1}\right)$ diterima yang berati ada hubungan positif antara peer group dengan pre married syndrom pada wanita di Desa Sriwulan.

b. Ha pada variabrl (X3) diterima yang berati ada hubungan positif antara faktor pendidikan dengan pre married syndrom pada wanita di Desa Sriwulan. 
c. Ha pada variabel $\left(\mathrm{X}_{3}\right)$ diterima yang berati ada hubungan positif antara konsumsi media dengan pre married syndrom pada wanita di desa sriwulan.

4. Hubungna antara variabel $(\mathrm{X})$ dengan pre married syndrom ( $\mathrm{Y}$ ) di desa Sriwulan signifikan dengan nilai:

a. Peer group dengan pre married syndrom pada wanita di Desa Sriwulan dengan nilai $t_{\text {penelitian }}>t_{\text {tabel }}$ $-1,099>0,67720$

b. Faktor pendidikan dengan pre married syndrom pada wanita di Desa Sriwulan dengan nilai $t_{\text {penelitian }}$ $>t_{\text {tabel }}=-2.275>1.98638$

c. Konsumsi media dengan pre married syndrom pada wanita di Desa Sriwulan dengan nilai $t_{\text {penelitian }}$ $>t_{\text {tabel }}=4.022>2.36803$

5. Hubungan antara faktor determinan dengan pre married syndrom pada wanita di Desa Sriwulan untuk $\mathrm{X}_{1}$ sebesar - 0,70782 adalah hubungan yang kuat, $\mathrm{X}_{2}$ sebesar -0,5394 adalah hubungan yang sedang, $\mathrm{X}_{3}-0,5320$ adalah hubungan yang sedang.

\section{DAFTAR PUSTAKA}

DeVito, Joseph A.(1997). Komunikasi antar Manusia. Jakarta.: Profesional Books.

Gunarso, Singgih D.(2007). Psikologi Remaja. Jakarta : PT Tunas Jaya Lestari.
Huraerah, Abu. Dinamika kelompok, konsep dan aplikasi. Bandung : Refika Aditama.

Bachtiar, A. (2004). Menikahlah, Maka Engkau Akan Bahagia!. Yogyakarta : Saujana.

Silalahi, U. (2012). Metode Penelitian Sosial. Bandung: PT Refika Aditama.

West, Richard dan Lynn H (2008). Pengantar Teori Komunikasi, Analisis dan aplikasi. Jakarta: Salemba Humanika

Santosa, Slamet. (1999). Dinamika Kelompok. Jakarta: Bumi Aksara.

Zaitun,M. Ag. (2009) .Sosiologi Pendidikan. Pekanbaru: Mahkota Riau.

Notoatmodjo, Soekidjo. (2003). Pendidikan dan Perilaku Kesehatan. Jakarta : PT Rineka Cipta

Badan Pusat Statistik Kab. Demak

Internet:

http://malezones.com/artikel/berapakah-usiaideal-untuk-menikah.html (di akses : senin, 7 okt 2013 18:55)

http://www.harianorbit.com/usia-ideal-wanitauntuk-menikah/ ( diakses, senin, 7 Okt 2013 19:00 )

http://newslifestyle4u.blogspot.com/2013/06/5alasan-wanita-lebih-memilih-karir.html ( di akses, senin, 7 Okt 2013 19:18 )

http://www.sarjanaku.com/2013/01/pengertianperkawinan-makalah-masalah.html (diakses, rabu, 8 